\title{
Erratum zu: \\ Einfluss nachhaltiger Projektattribute auf Kosten, Mieten und Werte
}

Erratum zu:

Kapitel 4 in: C. Kraft und C. Kempf, Nachhaltige Wohnungswirtschaft in der Schweiz, https://doi.org/10.1007/978-3-658-34808-3_4

Trotz sorgfältiger Erstellung unserer Bücher lassen sich Fehler nicht vermeiden, daher weisen wir auf Folgendes hin:

Kapitel 4, S. 95: Aufgrund eines technischen Fehlers während der Buchherstellung wurde die Abb. 4.6 nicht korrekt dargestellt. Die Abbildung wurde durch ein Erratum korrigiert, die ebenfalls in diesem Kapitel zu finden ist.

Die aktualisierte Versionen die Kapitel sind verfügbar unter https://doi.org/10.1007/978-3-658-34808-3_4

(C) Der/die Autor(en), exklusiv lizenziert durch Springer Fachmedien Wiesbaden GmbH, 


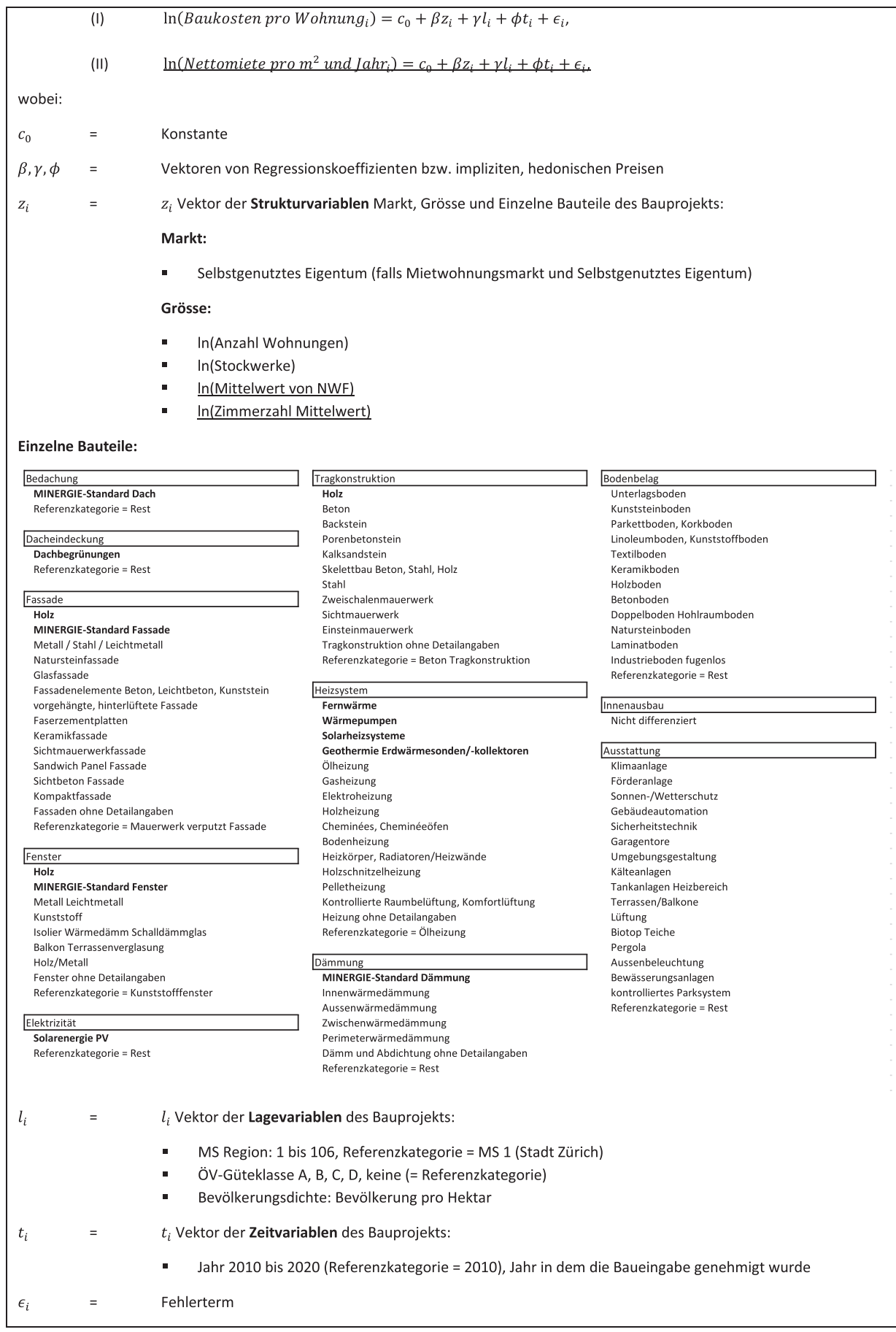

Abb. 4.6 Modellbeschrieb 